\title{
(Meta-) Methodological Lessons for Ethics Consultation
}

\author{
Mark P. Aulisio
}

\section{Introduction}

At the outset of this chapter, I want to echo the praise offered by all of the contributors to this volume for Finder's outstanding, thoughtful and self-critical narrative of the case of 83 year old Mrs. Hamadani and her fiercely devoted children. The brocade account is carefully woven, like a fine Persian tapestry, to convey the rich complexity of an actual ethics consultation as it transpires not over hours, but rather over days, weeks, months and even, as in this case, years. Mrs. Hamadani's narrative so told is replete with questions worthy of critical reflection. What is an appropriate role for ethics consultation in healthcare? How can an autonomy-centric culture accommodate community-centric cultural difference? How can or should the voice of the patient be heard when she cannot speak for herself and the much louder and anguished voices of others demand to be heard? What are the bounds of acceptable medical treatment and how should care teams respond when patient or family demands threaten to push care givers to cross those bounds? What is an appropriate response for ethics consultants when they are asked to take over a case or prevent a colleague from interacting with an unwilling family? Do the motivations of patients, family, or members of the care team in calling ethics consultants necessarily shape the consultant's role? And so the list goes on, as the variety of commentaries which comprise the majority of this volume, as well as the multitude of discussions that you, the readers, will inevitably have with colleagues, students, and friends make abundantly clear.

Rather than attempting to answer any of these questions, my aim here will be suitably modest. That is, I hope to contribute to what will undoubtedly be an ongoing

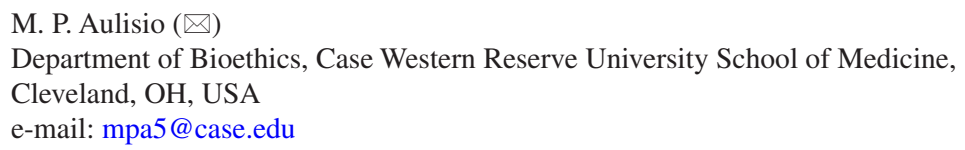


conversation by offering a few reflections on the Hamadani case - reflections evoked by Finder's telling of Mrs. Hamadani's story - and their lessons for method in ethics consultation. These lessons might be better characterized as meta-methodological because they are at a level of generality that makes them, I think, compatible with and relevant for a wide variety of more specific models, approaches and methods for doing ethics consultation in healthcare settings. The reflections and their metamethodological lessons concern underlying value conflict or uncertainty, decisionmaking authority, and focus of care.

\title{
Value Conflict or Uncertainty?
}

\begin{abstract}
"None of us thought she would live this long, and Nadira and I have spent much of this time making sure that our mother is taken care of, that we do for her what she did for us, for all of us, even including our father, in the past. Although I have lived here in the United States for almost 30 years, I still hold fast to some of the values that come from our homeland. And respecting and caring for one's parents is high on the list. Unfortunately," and here she began to trail off, "many here do not share this belief." (Finder 2018: 32-3; emphasis added).
\end{abstract}

Thus Farzana Hamadani, the elder of the patient's two daughters, starkly articulates a difference in cultural values that, in her eyes, underlies so much of the struggle that she, her sister, Nadira, and brother, Samir Zadeh, have had in their nearly 4 year ordeal of caring for their mother, Mrs. Hamadani. Though she did not explicitly state it, it is clear from nature and number of conflicts with health professionals over these years that the struggle was often, in their eyes, made more, not less, difficult by the very people who were supposed to be caring for her mother. Indeed, we are told that upon Mrs. Hamadani's first admission to the hospital over 3 years earlier, a neurologist suggested hospice placement as a possibility for her only to be shouted out of the room, chased down the hall, and "fired" (Finder 2018: 22). At the time Mrs. Hamadani had newly diagnosed cancer, with metastases to her liver and brain, advanced Parkinson's, congestive heart failure, and renal insufficiency, making the hospice suggestion completely understandable. Despite this, the suggestion of hospice care was taken as disrespectful and uncaring, at worst, or callous, at best. Compounding the effrontery, the family believes that their mother has now had over 3 years with them and their father - years which surely she would not have had if they had not protected her from the uncaring neurologist.

At other points too, we are told, Mrs. Hamadani had need of the protection of her family against "care" providers; even on this admission. Samir in his impromptu first encounter with Finder relays,

My mother, she is strong and after only a few days in the ICU she was well enough to go back to the floor. But the nurses there, they were not as attentive as the staff in the ICU, and my sister, Nadira, or our older sister, Farzana, or I would have to make sure they gave her medicines on time and that they fed her correctly. Let me tell you Dr. Finder, we had to watch out or she would not get the care she needs to get stronger. (Finder 2018: 24-5; emphasis added) 
And

And then today, my mother was not doing so well, and it is, I believe, because they have not been giving her enough nutrition and so she is weak. And she began to have difficulty breathing and she had to be emergently taken back to the ICU. (Finder 2018: 25; emphasis added)

As the family continues to protect Mrs. Hamadani from the care team, they become, true to Farzana's words, care-providers themselves. From feeding to removing the Bipap mask to carefully monitoring every health professional interaction with their mother, Samir, Farzana and Nadira continue to "respect and care" for her. The move from protector to active care-provider, even while Mrs. Hamadani is hospitalized, is a relatively short one. After all, if "many here" do not share the value of "respecting and caring for one's parents," how much less might they respect and care for another's parents?

Not surprisingly, the value difference underscored by Farzana in the passage quoted at the outset of this section is repeatedly echoed by Samir in his conversations with Finder and affirmed by Nadira and Farzana's behavior. From Samir's initial conversation about Finder's colleague, Dr. Moore, who was the first ethics consultant on the case, to his subsequent quasi-firing of Finder at the final family meeting there is tension about "respecting and caring for" one's parents:

"But Dr. Finder," Mr. Zadeh continued, "your Dr. Moore, he has pestered us, always showing up when my mother has come into the hospital, asking us if we are ready to stop. It's as if he doesn't know what it means to love your mother" ... Mr. Zadeh's sister, Nadira, was gently wiping her eyes as Mr. Zadeh spoke. (Finder 2018: 25; emphasis added)

I do not want my mother to suffer, no one should ever want their mother to suffer. I do not need to hear 'we do not want your mother to suffer.' What I want is for my mother to be taken care of, and when the time comes to make a decision, my sisters and I will decide, and we will do what is best for our mother... The doctors need to take care of my mother, the nurses need to do what they are supposed to do, and we, as the family, we will make the decisions that we need to make. OK? (Finder 2018: 41; emphasis added)

Most of us would be quite taken aback, even offended, if we were told that "respecting and caring for one's parents" is not a value in our culture; more so if told it is not a value for us. Despite this, it is clear that this is precisely what Mrs. Hamadani's children believed both with respect to the broader cultural context and even more poignantly, that of healthcare. Given this belief, it is more than understandable that the Hamadani children would be compelled to stand watch, as sentinels, protecting her. A more plausible, and to most of us more palatable, explanation of the value laden cultural difference in the Hamadani case, however, is that the difference was less over the value of respecting and caring for one's parents and more over what it means to respect and care for ones parents, particularly in a healthcare context at a major medical center in the United States.

To unpack this a bit more, the two sides (a false binary but an easier way to speak of it) each interpreted differently what the values of "respecting and caring for" required in the case of Mrs. Hamadani. For members of the care team, respecting and caring for Mrs. Hamadani meant shifting the goals of care, sooner rather than 
later, to comfort; seeing to it that the dying process was shorter, rather than longer; and ensuring that Mrs. Hamadani was as free of pain and suffering as possible within the limits of acceptable medical practice. For the Hamadani family, respecting and caring for Mrs. Hamadani meant fighting disease as she was a "fighter" giving her as much "extra time" with them as she could have; directly providing care to her as they were able and as she had done for them for so many years; and keeping vigil until a decision was forced upon them.

If this analysis is correct, a deep value-laden difference about what it meant to "respect and care for" Mrs. Hamadani, and not about whether one should respect and care for her, was at the core of the Hamadani case. This difference was, to be sure, partly a function of culture, but I would suggest that it was also partly a function of the radically different role relationships of daughter or son, on the one hand, and healthcare professional, on the other. I suspect that this is one of the reasons this type of value conflict or uncertainty is sometimes present in cases in which there is no discernible cultural difference. Respecting and caring for one's parent and respecting and caring for one's patient need not, even stronger - should not, be the same. Mrs. Hamadani needed her devoted children caring for her as only children can, but she also needed devoted doctors, nurses, social workers, and care team members caring for her as their respective professional roles require. Early identification of differences in the meaning of "respecting and caring for" and analysis of its possible sources might have allowed those involved to better understand each other and move forward with less conflict. It might have also, over time, laid the groundwork for building a consensus among those involved to move forward in a way that may have made a difficult and burdensome case perhaps a little less so.

The first meta-methodological lesson from "The Zadeh Scenario," then, is that however one does ethics consultation, one of its core elements is to identify and analyze the nature of the values conflict or uncertainty that underlies the need for consultation. ${ }^{1}$ Not explicitly doing this in the Hamadani case may be a methodological hazard of the heavily phenomenological approach so expertly employed by Finder (and presumably by Dr. Moore as well). While many of us no doubt fail to pay sufficient attention to the texture of the case as Finder does exceptionally well, it is also important to step back and abstract a bit from the concrete messiness and time pressures of the actual case to surface possible underlying issues, particularly those with important normative dimensions.

\footnotetext{
${ }^{1}$ Indeed, the first of two core features in ASBH's "ethics facilitation approach" is "to identify and analyze the nature of the value conflict or uncertainty underlying the consultation" (ASBH 1998, 2011; Aulisio et al. 2000). Elsewhere I have argued that ASBH's "Ethics Facilitation" approach is best understood as a more general normative characterization of ethics consultation that is informed by the context in which ethics consultation is done and is compatible with a wide variety of models and methodologies, among which is included phenomenological method as practiced by Dr. Finder and, presumably, Dr. Moore (Aulisio 2011). I should also add that not all cases that come to ethics consultation necessarily involve underlying value conflict or uncertainty, but helping to sort even this out is a valuable service.
} 


\section{Decision-Making Authority?}

Above I suggested that a certain understanding of what it means to respect and care for one's parents along with familial and health professional role differences (at least partly) drove the Hamadani family to think that the value of respecting and caring for one's parents was somehow not shared by society in general or by members of the care team in particular. Such a belief makes very understandable their strong adoption of the protector and provider role on behalf of their mother. Just as protecting leads quickly and understandably to providing, "providing" leads quickly to "deciding." A recurring theme in "The Zadeh Scenario" as told by Finder is that there was an ongoing struggle, at least in the eyes of the Hamadani family, about decision-making. Interestingly, the struggle was not primarily about who would make decisions (except in one encounter), but rather about what decisions should be made and when they should be made.

Members of the care team, Drs. Moore and Finder, and the Hamadani family alike seem to be largely in agreement that the Hamadani children are the appropriate decision makers for Mrs. Hamadani. Disagreements emerge primarily over the content and timing of such decisions. For example, the first time decision-making is broached in the narrative, it is because members of the care team are concerned that Mrs. Hamadani's children are making "bad decisions" in their single minded determination to pursue aggressive, rather than comfort, care for Mrs. Hamadani (Finder 2018: 23). Similarly, when questions are raised about DNR status (an often contentious point between care team and family members) we are told time and again by members of the care team that the family is "not ready to make that kind of decision" (Finder 2018: 24; or the equivalent: 24, 26, 27, 28) or that they have put off a decision when approached by saying "now is not a good time" (multiple times; Finder 2018: 24, 28, 30, 31, 36, 40, 41).

To the extent that the Hamadani family had settled on anything, it appears that it was that they would pursue aggressive care as long as possible and make a decision about resuscitation (and all that it entails) only if their mother's heart stopped and such a decision was necessary. Dr. Broukhim's notes make this clear, as Finder writes:

The notes for Mrs. Hamadani gave a very clear picture of all that had been going on, including his own assessment that Mrs. Hamadani was no longer a candidate for any kind of therapeutic interventions, that he had, since the beginning of this admission, been recommending a shift to a purely palliative focus, that the family seemed to understand that their mother was likely near the end of her life, but that they also were, as of yet, unwilling to consent to anything less than full code and that they continued to ask about what other options might be considered. (Finder 2018: 30; Broukhim note, emphasis added)

With all of that in his note, what stood out next was that he then reported that "the family does not, at this time, wish to have me write a DNAR order, that they prefer to wait until the decision to act must be made before giving permission not to proceed to intubation." (Finder 2018: 31; Broukhim note, emphasis added) 
The repeated attempts to encourage the family to consider and decide on, first, comfort measures and, later, code status, are supported by Samir's comments to Finder as well. He describes Dr. Moore's "checking in" about decision-making as "pestering" and "always showing up when we come to the hospital asking us if we are ready to stop" (Finder 2018: 25). Samir is equally clear about when and by whom a decision to resuscitate will be made in his conversation with Dr. Finder, "And I told them that no decision like that needed to be made until her hearts stops; then we, my sisters and I, will decide what to do!" (Finder 2018: 25) and "we will decide whether to put her on machines" (Finder 2018: 26).

In my experience, the above internecine dynamic is far from rare. Family members feel badgered and pressured for "a decision" that is in line with the care team's recommendation, especially when comfort measures only or, at the very least, DNAR are being considered. They also often feel that they are not being heard and that members of the care team are approaching them the way Dr. Moore approached the family in Samir's eyes: "he simply came to get us to say what he wanted to hear" (Finder 2018: 26). Within this adversarial dynamic, that the family is the locus of decision-making or, more directly, that decision-making authority lies with the family is repeatedly affirmed and, ultimately, entrenched. Once entrenched, the struggle to "convince" the family commences. These struggles usually result in much collateral damage, not the least of which is the patient's voice cannot be heard above the din.

This internecine dynamic is set up by a mistake. The mistake is placing the locus of decision-making with the family. One of the fundamental normative features of our societal context, a context within which clinical ethics consultation is practiced, is that decision making authority for the once capacitated but now incapacitated patient rests squarely with the patient, i.e., the patient is the locus of decisionmaking. This is a function of a patient's right to live according to his or her own values, which values may have implications for medical decision-making (Aulisio 2003, 2014). Decision-making authority remains with Mrs. Hamadani, not with the care team or with the family. This is not to say that each of the latter do not have a role to play, far from it. The family's (surrogate's) role is to try to help make clear the values of the patient and what they might mean for decision-making. ${ }^{2}$ The care team's role is, among other things, to articulate the range of medically acceptable options, as well as to be clear about their recommended option in the event that they have one.

The second meta-methodological lesson from "The Zadeh Scenario" is, then, that early on it is imperative that all concerned focus on the appropriate source for decision making authority and what that means for the role of family (surrogates) and care team in decision making. A good mechanism for ensuring such a focus is to hold a multidisciplinary team meeting followed by a family conference very early

\footnotetext{
${ }^{2}$ Elsewhere, I have argued that we should drop "decision-maker" when discussing the surrogate's role because it falsely connotes that surrogates are decision makers in a straightforward sense. This is, as I will discuss in the next section, confusing for health professionals and extremely burdensome for surrogates (Aulisio 2016).
} 
in the patient's stay. This is not a panacea for difficult cases, as difficult cases will remain, well, difficult. Relative clarity about decision-making roles can, however, allow for more open lines of communication and, perhaps, serve as a prophylactic against the internecine dynamic characterized above.

\section{Focus of Care?}

My last reflection concerns a striking, albeit again all too common, feature of the Hamadani case. From Finder's narrative, it appears that as the case unfolded, the patient's family functionally became the patient, shifting not only the locus of decision-making but also the focus of care from Mrs. Hamadani to her devoted, but distressed and overburdened, children. This shift exacted a heavy toll from all concerned, most especially from the Hamadanis themselves.

Interestingly, there are no less than three points in the narrative when patient treatment decisions are made primarily for the family's benefit rather than the patient's. This constitutes what I would term the "family as patient" phenomenon. It first presents early in the narrative with Dr. Moore arranging for Broukhim to take over Mrs. Hamadani's care:

In an effort to help this family, Steve was the one who had actually contacted Dr. Broukhim to see if he'd be willing to talk with Mr. Zadeh and his sisters; Broukhim had a reputation of being extremely aggressive - often too much so for some of the other physicians who frequently interacted with him—but he was beloved by his patients. (Finder 2018: 22-3)

The key here for our purposes is that Dr. Moore ("Steve") contacted Broukhim "in an effort to help this family" thinking that Broukhim would be very aggressive in accord with his reputation and consonant with the family's wishes.

A second instance of a patient care decision being made primarily for the benefit of the family occurs just over 3 years later. In Mrs. Hamadani's final stay, Steve reprises this role again by supporting the placement of an NG tube against Broukhim's advice, "In an effort to defuse this moment, Steve had offered that perhaps it would not be unreasonable to place the NG, since it offered little risk and only minimal discomfort given Mrs. Hamadani's state" (Finder 2018: 24). We are told that the "gamble... paid off in that Mr. Zadeh expressed appreciation to Steve for supporting their wishes for the NG" tube (Finder 2018: 24; emphasis added).

A third instance of treatment decisions being made primarily for the family's benefit occurs toward the end of the narrative and concerns the possibility of dialyzing Mrs. Hamadani. Despite the fact that the ICU attending (Dr. Smith), the consulting nephrologist (Dr. Nadouri) and Dr. Broukhim himself recommended against it, the family was insistent that dialysis be considered (Finder 2018: 31). In recounting Broukhim's note, Finder tells us

Moreover, he reported a similar disposition regarding dialysis. And in the same breath (so to speak), he then wrote that he asked Dr. Nadouri to get a second renal consultant to take a look at Mrs. Hamadani in order to help determine if dialysis would be helpful. (Finder 2018: 31) 
Thus, we are told that Dr. Broukhim agreed with the determination of the attending and the consulting nephrologist regarding the inappropriateness of dialysis but, nonetheless, requested that a second nephrologist be consulted solely, so far as we can tell, at the behest of the family. The day after reading Broukhim's detailed note on this matter, Finder met with him only to find out that the second nephrology consult (with Dr. Spector) yielded a very different result: Dr. Spector thought that a short trial of dialysis might be useful as it might address possible uremic encephalopathy (Finder 2018: 35) and thereby slightly improve mental status. To Finder's surprise, Broukhim accepted the assessment even though it was contrary to that of two other physicians and his own prior medical judgment. Furthermore, he queried Finder as to whether he thought a trial of dialysis would be reasonable. After some discussion, Broukhim offers the following conclusion,

"I think with all that they've been through," Broukhim now said, "it's not unreasonable to see if we can wake her up and give them a chance to have a little bit a final time together. She's been a real fighter all along, and they've been so involved in her care, I think I owe them this." (Finder 2018: 35; emphasis added)

The decision to dialyze Mrs. Hamadani had been made primarily, although not exclusively, for the benefit of her children.

These three examples of care decisions being made primarily for Mrs. Hamadani's children highlight what is, for me, a prominent theme in this powerful narrative.: somehow over the course of Mrs. Hamadani's 3-plus years after being diagnosed with metastatic cancer and her multiple admissions to the hospital, Mrs. Hamadani's children gradually became "the patient." Not only were they viewed as the source of decision making authority, they were also increasingly viewed as the proper subject of care, "the patient," in their own eyes and those of the care team. The narrative provides scores of examples of this. Indeed, at the conclusion of Finder's initial chance involvement with the family, Mr. Zadeh says to him,

"You are a good listener, Dr. Finder, and I thank you. I believe you understand what it is like to face this sort of thing." And then he (Mr. Zadeh) said it: "And so I beg of you, Doctor, please don't let Dr. Moore see my mother again. My sisters and I do not want him talking with us anymore." (Finder 2018: 26; emphasis added)

And regarding this, Finder tells us,

And for a second time since exiting the elevator and walking outside, I was taken aback somewhat. While there was a kind of forcefulness to Mr. Zadeh's request, as he spoke it, both he and his sister Nadira were both looking at me not with anger nor reproach, but with eyes slightly wide and down-turned at the corners. I was struck by their sadness and apprehension, peppered with a bit of fear. (Finder 2018: 26; emphasis added)

Mr. Zadeh's request to Dr. Finder that Dr. Moore no longer be involved in the case is fundamentally about the distress Moore's involvement is causing the family to experience. When Finder accedes to this request, he discovers upon visiting with Nadira and Farzana that the family is extremely appreciative of his having helped make "sure that Dr. Moore is no longer a bother" to them (Finder 2018: 32).

Interestingly, Dr. Broukhim in one of his notes makes clear that he personally asked Dr. Moore to stay involved in the case to, among other things, "provide as 
much support to the family" as he could (Finder 2018: 30). The family clearly did not feel supported by Dr. Moore as he, in the words of Mr. Zadeh, "did not visit, he simply came to get us to say what he wanted to hear" (Finder 2018: 26). Later, the family expresses appreciation to Dr. Finder for "visiting" with them (contra Moore) (Finder 2018: 34). In some ways Finder's role was really about being present to and "visiting" with those who are suffering - the patients - Mrs. Hamadani's children. Dr. Finder, like Dr. Moore before him, is ultimately, in a sense, fired from the case when his presence no longer eases the family's suffering and, perhaps, piques it when he shifts the focus again in his final comments to what is going to happen to Mrs. Hamadani and his concern that she not suffer:

"You know, Dr. Finder," said Mr. Zadeh, "I think you are right. But the problem here is that
everyone keeps telling me and my sisters all these bad things about what is going to happen
to our mother as if we do not understand. But we do understand, we are not uneducated
people. But is it too much to ask to please stop preaching about what is going to happen to
our mother? We understand, we know, we get it!" His voice was now raised, and Farzana
reached over as if to calm him, but he was in the grip of the moment, of release, perhaps.
(Finder 2018: 41)

And later,

He paused and then added, "Please Dr. Finder, I do not wish to cause problems, and I apologize for raising my voice. But I do not want to talk about this anymore and I do not want to talk with anyone else but Dr. Broukhim." (Finder 2018: 41)

Whether family, significant other, or friend, all those who deeply care about the patient are vulnerable, stressed, and burdened - they are suffering - and, as such, especially in a protracted case, they become de facto patients. They might be termed something like second order or secondary patients, because their suffering is largely a function of their concern for their loved one, the (first order or primary) patient. As family members et al. become secondary patients, all involved run the risk of affording them the status of (primary) patients with potentially devastating consequences. That status includes many of the features of the Hamadani case as discussed above, not the least of which is that family members become the decision makers (as if they were the patient) and treatment decisions start to be made primarily out of concern for the impact on the family and in accord with the family's concerns rather than patient values.

The empirical literature is now filled with examples of the heavy burdens shouldered by surrogate decision-makers (see, for example, Wendler and Rid 2011). The growing literature on surrogate decision making underscores the severe nature of this burden. In a study of family members of 294 ICU patients, for example, 33.1\% of all family members exhibited symptoms consistent with moderate to major risk of developing Post-Traumatic Stress Disorder (Azoulay et al. 2005). The percentage jumped to $47.8 \%$ for family members who "shared in decision making" and a stunning $81.8 \%$ for family members who "shared in end of life decisions." Another study of 30 surrogates in five ICUs found that surrogates experience "significant emotional conflict between the desire to act in accordance with their loved one's values and 1) not wanting to feel responsible for a loved one's death, 2) a desire to 
pursue any chance of recovery, and 3) the need to preserve family well-being" (Schenker et al. 2012). From the narrative, there can be little doubt that Samir, Nadira, and Farzana experienced significant emotional conflict about competing concerns and likely exhibited symptoms of Post-Traumatic Stress Disorder as well.

The third and final meta-methodological point is that many of the cases brought to ethics consultation will inevitably involve families or loved ones who are secondary patients. All of us who perform clinical ethics consultation need to be careful that the patient's family or loved one's do not functionally become the (primary) patient, shifting not only the locus of decision-making but also the focus of care as appeared to happen in the Hamadani case. In order to avoid this, we have to acknowledge the emotional needs of family members and loved ones, marshaling all support resources at our disposal (pastoral care ministry, social work, bereavement groups, counseling services, etc.) to attend to those needs. In addition, as I have argued above and elsewhere, we need to work to make clear early on that patients, not family members, other surrogates or even health professionals, are the locus of decisionmaking authority in our societal context due to the rights of individuals to live by their own values. In a real sense, once capacitated but now incapacitated patients remain the decision makers with the rest of us playing a support role in seeing to it that any decisions made reflect those values within the bounds of medically appropriate care. Taking this normative feature of our societal context seriously means we should not approach family members or loved ones for a "decision" or "consent" or ask "what do you want us to do?" We should, rather, frame issues over and against clearly articulated surrogate, team member and patient roles in which, whatever else is entailed, the patient is accepted as the clear source of decision making authority and focus of care.

\section{References}

American Society for Bioethics and Humanities (1998) Core competencies for health care ethics consultation: the report of the American Society for Bioethics and Humanities, 1st edn. ASBH, American Society for Bioethics and Humanities, Glenview, pp 3-10

American Society for Bioethics and Humanities (2011) Core competencies for health care ethics consultation: the report of the American Society for Bioethics and Humanities, 2nd edn. ASBH, American Society for Bioethics and Humanities, Glenview, pp 2-10

Aulisio MP (2003) Meeting the need: ethics consultation in health care today. In: Aulisio MP, Arnold RM, Youngner SJ (eds) Ethics consultation: from theory to practice. Johns Hopkins University Press, Baltimore, pp 1-22

Aulisio MP (2011) "Facilitated consensus," "ethics facilitation," and unsettled cases. J Clin Ethics 22(4):345-353 author reply 358-362

Aulisio MP (2014) Advance directives and the physician-patient relationship: a surprising metamorphosis. In: Lack P, Biller-Adorno N, Brauer S (eds) Advance directive. Springer, Dordrecht, pp $127-152$

Aulisio M (2016) "So what do you want us to do?" Patients' rights, unintended consequences, and the Surrogate's role. Oxford Handbooks Online. Retrieved 23 Jan. 2016, from http://www.oxfordhandbooks.com/view/10.1093/oxfordhb/9780199974412.001.0001/ oxfordhb-9780199974412-e-13 
Aulisio MP, Arnold RM, Youngner SJ (2000) Health care ethics consultation: nature, goals, and competencies. A position paper from the Society for Health and Human Values-Society for Bioethics Consultation Task Force on Standards for Bioethics Consultation. Ann Intern Med 133(1):59-69

Azoulay E, Pochard F, Kentish-Barnes N et al (2005) Risk of post-traumatic stress symptoms in family members of intensive care unit patients. Am J Respir Crit Care Med 171(9):987-994

Finder SG (2018) The Zadeh scenario. In: Finder SG, Bliton MJ (eds) Peer review, peer education, and modeling in the practice of clinical ethics consultation: the Zadeh project. Springer, Cham, pp 21-42

Schenker Y, Crowley-Matoka M, Dohan D, Tiver GA, Arnold RM, White DB (2012) I don't want to be the one saying 'we should just let him die': intrapersonal tensions experienced by surrogate decision makers in the ICU. JGIM 27(12):1657-1665

Wendler D, Rid A (2011) Systematic review: the effect on surrogates of making treatment decisions for others. Ann Intern Med 154(5):336-346

Open Access This chapter is licensed under the terms of the Creative Commons Attribution 4.0 International License (http://creativecommons.org/licenses/by/4.0/), which permits use, sharing, adaptation, distribution and reproduction in any medium or format, as long as you give appropriate credit to the original author(s) and the source, provide a link to the Creative Commons license and indicate if changes were made.

The images or other third party material in this chapter are included in the chapter's Creative Commons license, unless indicated otherwise in a credit line to the material. If material is not included in the chapter's Creative Commons license and your intended use is not permitted by statutory regulation or exceeds the permitted use, you will need to obtain permission directly from the copyright holder. 